\title{
Entoprocta-sponge associations in the Indian Ocean
}
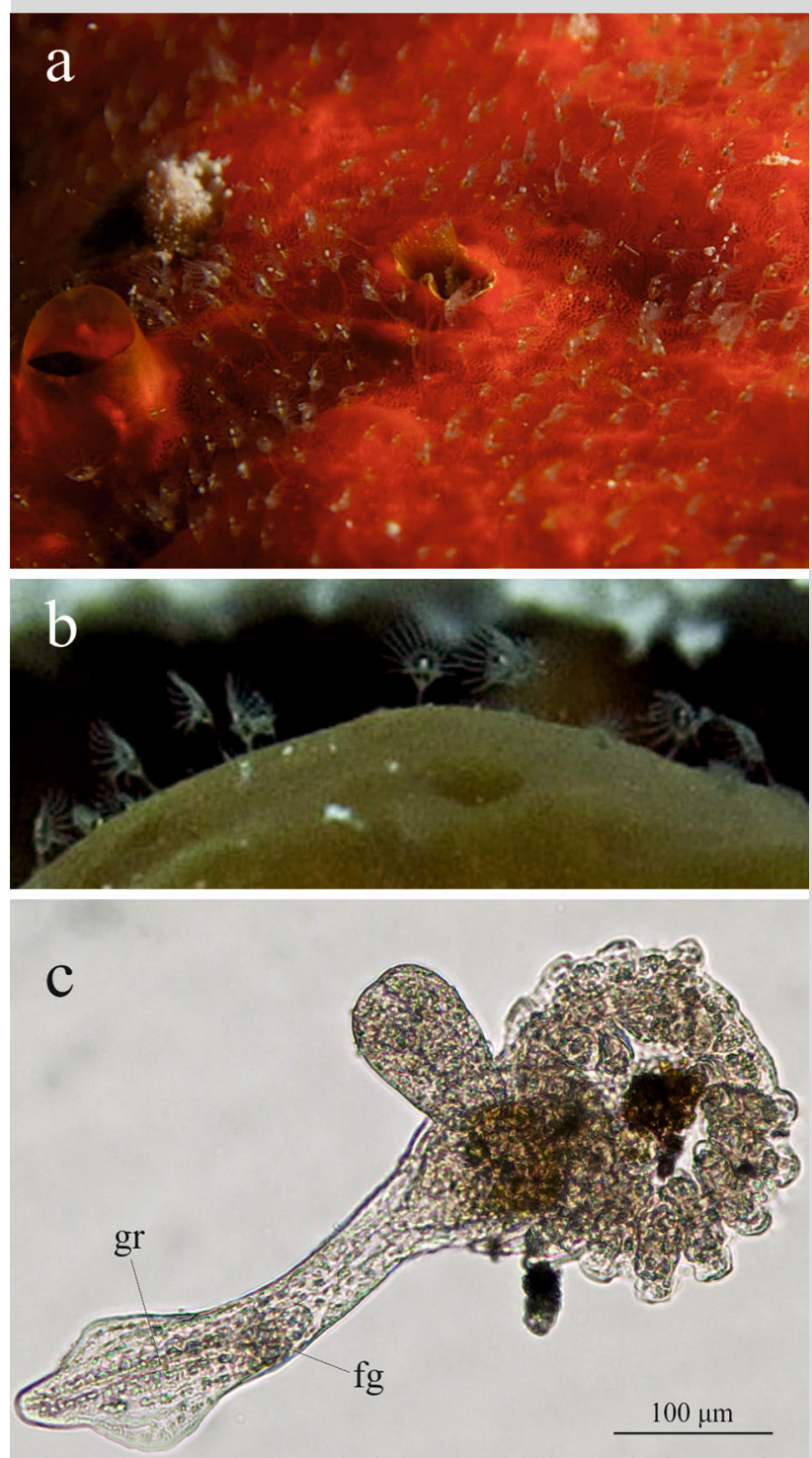

Fig. 1 a Clathria sp. colonized by many entoproct zooids. b High magnification of Petrosia sp. showing individual entoproct zooids extending their tentacles. c Specimen of Loxosomella sp. found in association with Clathria sp. $f g$ foot gland, $g r$ foot groove
The phylum Entoprocta is one of the most enigmatic groups of living invertebrates, although approximately 200 species are currently recognized (Nielsen 2013). Entoprocts are suspension feeders distributed worldwide, and most species live epizooically on other marine organisms (Iseto 2010). The only association recorded from the Indian Ocean is represented by three species belonging to the genus Loxosoma, associated with tube-building polychaetes found in Thailand (Nielsen 1996). During a recent biodiversity survey on Kunfunadhoo Island, Baa Atoll, Maldives $\left(05^{\circ} 07^{\prime} \mathrm{N}, 73^{\circ} 04^{\prime} \mathrm{E}\right)$, entoproct zooids were found in association with four genera of sponges-Cliona, Clathria, Dragmacidon and Petrosia - at depths of 5-32 m (Fig. 1a, b). Morphological analyses of all sponge-associated entoprocts revealed the presence of a foot-like appendage with a foot gland (fg) and groove (gr) at the base of the stalk (Fig. 1c), which are two distinctive features of the solitary genus Loxosomella (Iseto 2010). To the best of our knowledge, this is the first record of an association between Loxosomella and sponges in the Indian Ocean, as well as the first discovery of the phylum Entoprocta in the Maldivian archipelago. Organisms such as entoprocts are often overlooked in the field because of their small size $(0.2-5 \mathrm{~mm})$. Therefore, we strongly recommend additional ecological investigations of interspecific interactions involving tropical entoprocts and morpho-molecular studies targeted to detect the real diversity of this phylum. Our findings confirm that coral reef-associated biodiversity and the potential benefits and disadvantages of interspecific interactions remain insufficiently explored in the Indian Ocean.

Acknowledgments We thank the Soneva Fushi Resort, the Soleni Dive Center and the University of Milano-Bicocca for their support and effort on this research. Finally, we are grateful to two anonymous reviewers for their constructive comments.

\section{References}

Iseto T (2010) Comparative morphology of the foot structure of four genera of Loxosomatidae (Entoprocta): implications for foot functions and taxonomy. J Morphol 271:1185-1196

Nielsen C (1996) Three new species of Loxosoma (Entoprocta) from Phuket, Thailand, with a review of the genus. Zool Scr 25:61-75

Nielsen C (2013) Entoprocta. Encyclopedia of life sciences. Wiley, Chichester. doi:10.1002/9780470015902.a0001596.pub2

\section{A. Giorgi $(\bowtie) \cdot$ M. Monti · P. Galli · S. Montano}

Marine Research and High Education Center (MaRHE), Magoodhoo Island, Faafu Atoll, Republic of Maldives e-mail: aurora.giorgi88@gmail.com

P. Galli · S. Montano

Department of Biotechnologies and Biosciences, University of Milan-Bicocca, Piazza della Scienza 2, 20126 Milan, Italy

Received: 2 December 2015/ Accepted: 4 February 2016/Published online: 15 February 2016

Coral Reefs (2016) 35:611

(C) Springer-Verlag Berlin Heidelberg 2016 DOI $10.1007 / \mathrm{s} 00338-016-1418-\mathrm{z}$ 